\title{
Thermochemical Characterization of Casamance Biomass Residues for Production of Combustibles Briquettes
}

\author{
Mamadou S. Ba ${ }^{1 *}$, Lat G. Ndiaye ${ }^{1}$, Issakha Youm² \\ ${ }^{1}$ Laboratoire de Chimie et de Physique des Matériaux, Université Assane Seck, Ziguinchor, Sénégal \\ ${ }^{2}$ Centre d'études et de recherches sur les énergies renouvelables de Dakar, Hann Bel-Air, Dakar, Sénégal \\ Email: m.ba2667@zig.univ.sn
}

How to cite this paper: Ba, M.S., Ndiaye, L.G. and Youm, I. (2019) Thermochemical Characterization of Casamance Biomass Residues for Production of Combustibles Briquettes. Open Journal of Physical Chemistry, 9, 170-181.

https://doi.org/10.4236/ojpc.2019.93009

Received: June 22, 2019

Accepted: August 12, 2019

Published: August 15, 2019

Copyright () 2019 by author(s) and Scientific Research Publishing Inc. This work is licensed under the Creative Commons Attribution International License (CC BY 4.0).

http://creativecommons.org/licenses/by/4.0/

\begin{abstract}
The development of alternatives energies illustrates the common interest of all countries in reducing greenhouse gas emissions and combating climate change. Thermochemical treatment of municipal solid waste, agricultural and forestry wastes is a major challenge for this $\mathrm{XXI}^{\text {st }}$ century to replace petroleum fuels. Thermogravimetric analysis (TGA) makes it possible to elucidate the thermal behavior of Casamance (Senegal) biomass residues, mass losses and decomposition rate, under inert $\left(\mathrm{N}_{2}\right)$ atmosphere and oxidizing $\left(\mathrm{O}_{2}\right)$ atmosphere. Carbonization and briquetting techniques of these various residues encountered in this part of Senegal country, by densification in order to produce fuel briquettes (call biochars) will be used to improve stoves for cooking. Samples used in this study are peanuts shells (PNS), cashew nut shells (CNS), palm nut shells (PLS) and millet stems (MS). Elemental and approximate analyses make it possible to determine the $\mathrm{CHNSO}^{*}$ composition, volatile matter, fixed carbon and ashes content of the samples used. Higher heating values (HHV) of the former residues are ranging from $28.60 \mathrm{MJ} \cdot \mathrm{kg}^{-1}$, $26.51 \mathrm{MJ} \cdot \mathrm{kg}^{-1}, 29.69 \mathrm{MJ} \cdot \mathrm{kg}^{-1}$ and $24.93 \mathrm{MJ} \cdot \mathrm{kg}^{-1}$ respectively. The chars are obtained by slow pyrolysis with a heating rate of $5^{\circ} \mathrm{C} \cdot \mathrm{min}^{-1}$ from ambient temperature up to $800^{\circ} \mathrm{C}$ under inert atmosphere. The morphology of the samples is different for the four biomasses studied, from biomass in the form of wood fibers to a more compact biomass. The parietal composition of different samples presented was determined by Van Soest method using neutral detergents (NDS), acid detergent (ADS) and sulfuric acid $\left(\mathrm{H}_{2} \mathrm{SO}_{4}, 72 \%\right)$; to solubilize successively extractable, hemicellulose and cellulose respectively; lignin was obtained by balance (Table 2). The samples show a high level of cellulose, this pseudo-component is very rich in carbon directly linked to the calorific value, whose values vary from $32.35 \% ; 24.20 \%$; $34.94 \%$ and $39.67 \%$
\end{abstract}


for PNS, PLS, CNS and MS respectively.

\section{Keywords}

Co-Products, Carbonization, Biochar, NDS, ADS and TGA

\section{Introduction}

In view of the predictable depletion of fossil resources and the environmental problems engendered by their consumption [1], the use of alternative energy sources is essential in order to continue meeting global energy needs while preserving the environment [2]. Biomass is today considered as the leading source of renewable energy and the most spread in worldwide. The thermochemical decomposition of biomass can be carried out in the number of ways such as pyrolysis, gasification and combustion [3], by varying operating conditions such as vapor residence time, heating rate and reactor configuration. Pyrolysis is a technical method used to produce a range of products in the form of solid, liquid and gaseous fuels.

Energy is the foundation of economic and social development and its access is a critical issue in the fight against poverty. Much of the population of Casamance doesn't have access to fossil fuels for lighting and cooking foods due to high rate of poverty. In 2014, the World Food Program, estimated poverty rate of $76.6 \% ; 68.3 \%$ and $66.8 \%$ respectively for the three regions Kolda, Sédhiou and Ziguinchor that make up the natural region of Casamance [4]. The idea of this study is to determine the thermophysical characteristics decomposition of biomass, making it possible to produce briquette fuels based on agricultural or forestry residues such as peanuts shells (PNS), cashew nut shells (CNS), palm nut shells (PLS) and millet stems (MS). Production of these biofuels contributes to meet their energy needs, to fight against poverty, but also climate change in relation to petroleum products. The main sources of energy used by this population are wood and charcoal, which cause deforestation and the disappearance of plants species. In rural areas, the primary energy is satisfied thanks to the wood drawn directly from the forest. The production of coal from wood has traditionally been done using the "meule casamançaise". To better meet demand and optimize the production of biofuels, it's essential to replace old methods with a new technique of carbonization of biomass "1fût" and product fuels briquette by "rotor press". The efficiency of new technologies is mainly based on the understanding and control of the processes taking place during the production of coals.

Biomass is generally composed of three main groups of natural polymeric materials: cellulose (around $50 \%$ on dry basis), hemicellulose $(10 \%-30 \%$ in wood and $10 \%-40 \%$ in herbaceous biomass on dry basis), and lignin (20\% $40 \%$ in wood and $10 \%-40 \%$ in herbaceous on dry basis) [3]. Cellulose $\left(\mathrm{C}_{6} \mathrm{H}_{10} \mathrm{O}_{5}\right)_{\mathrm{n}}$ 
and hemicellulose (D-xylose $\mathrm{C}_{5} \mathrm{H}_{10} \mathrm{O}_{5}$ and D-mannose $\mathrm{C}_{6} \mathrm{H}_{12} \mathrm{O}_{6}$ ) had respectively a fundamental elemental biomass. Lignin had $\mathrm{C}_{9} \mathrm{H}_{10} \mathrm{O}_{2}, \mathrm{C}_{10} \mathrm{H}_{12} \mathrm{O}_{3}$ and $\mathrm{C}_{11} \mathrm{H}_{14} \mathrm{O}_{14}$ respectively of the three types of monolignols in the form of p-hydroxyphenyl, guaiacyl and syringyl [5]. The lignocellulosic fraction of the four co-products studied in this paper was obtained by Van Soest method of extraction fiber using neutral detergent (NDS) and acid detergents (ADS) and sulfuric acid $\left(\mathrm{H}_{2} \mathrm{SO}_{4}\right.$, $72 \%)$. The thermogravimetric analysis (TGA) makes it possible to study and compare the thermal behavior of the samples and demonstrate the influence of certain parameters (chemical composition, heating rate, temperature, etc.) on reaction kinetics. TGA has been widely used to provide rapid quantitative methods for examination of processes under isothermal or non-isothermal conditions and for the estimation of the effective kinetic parameters for various decomposition reactions [6].

\section{Materials and Methods}

\subsection{Materials}

The four samples used in this study were two agricultural co-products of peanuts shell (PNS) and millet stem (MS), and two forestry co-products, cashew nut shell (CNS) and palm nut shells (PLS). The fluidized bed reactor allowed us to obtain pyrolysis chars at $800^{\circ} \mathrm{C}$ with a heating rate of $5^{\circ} \mathrm{C} \cdot \mathrm{min}^{-1}$ under inert atmosphere $\left(\mathrm{N}_{2}\right)$. The rotor-press is a dual-function reactor, either manually or electrically for biochar production. This reactor is used for the manufacture of biomass briquettes called biochars.

\subsection{Methods}

Elemental analysis of raw biomass co-products and torrefied char as well as their higher heating value, are presented in Table 1. The CHNS content was determined according to the CHNS250 method and the ash content was defined in accordance with standard NF M03-003. The oxygen content was also obtained by calculation whose sum of the percentage of elements revolves around $100 \%$. The calorific value was obtained via analysis by the calorimetric IKA ${ }^{\circledR}$ C5003 control.

The thermogravimetric analyses were carried out at $3 \mathrm{~L} \cdot \mathrm{h}^{-1}$ atmospheric pressure, under nitrogen or oxidizing atmosphere. The sample is placed in a platinum crucible, which is an isotherm at $30^{\circ} \mathrm{C}$ for $20 \mathrm{~min}$ then it is subjected to a rise in temperature with a heating rate of $5^{\circ} \mathrm{C} \cdot \mathrm{min}^{-1}$ at $800^{\circ} \mathrm{C}$. After isotherm at $800^{\circ} \mathrm{C}$ for $30 \mathrm{~min}$, the air or nitrogen supply vave is cut of allowing the cooling of the reactor to ambient temperature. Thermogravimetric analysis makes it possible to measure the mass variation of materials as a function of temperature and time in a controlled atmosphere. Its ideal use is to evaluate volatile content, thermal stability and thermal characteristics. The presence of a high water content tends to decrease its calorific value, because biomass becomes very reach in oxygen synonymous with $\mathrm{CO}_{2}$ emission. Depending on the type of biomass, the 
mass loss profile during the pyrolysis phase of a real biomass is similar to that cellulose or lignin. The pyrolytic behavior of biomass therefore depends on the proportion of cellulose and lignin in this biomass.

Plants and food products are made up of substances belonging to different categories of carbohydrates, lipids, proteins, minerals and very complex polymers such as lignin. The various components are dosed by series of extractions with alkaline and acidic reagents, each capable of extracting one component without destroying the others. For example, an NDF (Neutral Detergent Fiber) solution allows extracting only extracts (Figure 1). An ADF (Acid Detergent Fiber) solution makes it possible to solubilize the hemicelluloses whose product obtained consists mainly of cellulose and lignin. While the hydrolysis of the cellulose with $72 \%$ sulfuric acid destroys the cellulose leaving the lignin intact as brown-black powdery residue. In 2002, Martens determines in detail the influence of the different steps of the NDF determination method in order to minimize variations [7]. He makes it clear that careful washing of the residue with boiling water makes it possible to eliminate protein residues, lipid residues and other non-fibrous carbohydrates which otherwise remain attached to the fibers because they are highly viscous. Martens always states that the ADF solution mainly isolates celluloses and lignin, but not hemicellulose that degraded. In addition, some fast-fermenting pectins can precipitate in the cationic detergent, cetyl trimethylammonium bromide, allows the separation of proteins from the fibrous residue. Figure 1 shows the scheme of the extraction process of hemicelluloses, cellulose and lignin by detergents and sulfuric acid.

\section{Results and Discussions}

\subsection{Thermal Characteristic and Chemical Composition}

Table 1 shows the different values obtained during the elementary analysis and the proximate analysis of the four samples in the raw and in char state. The value

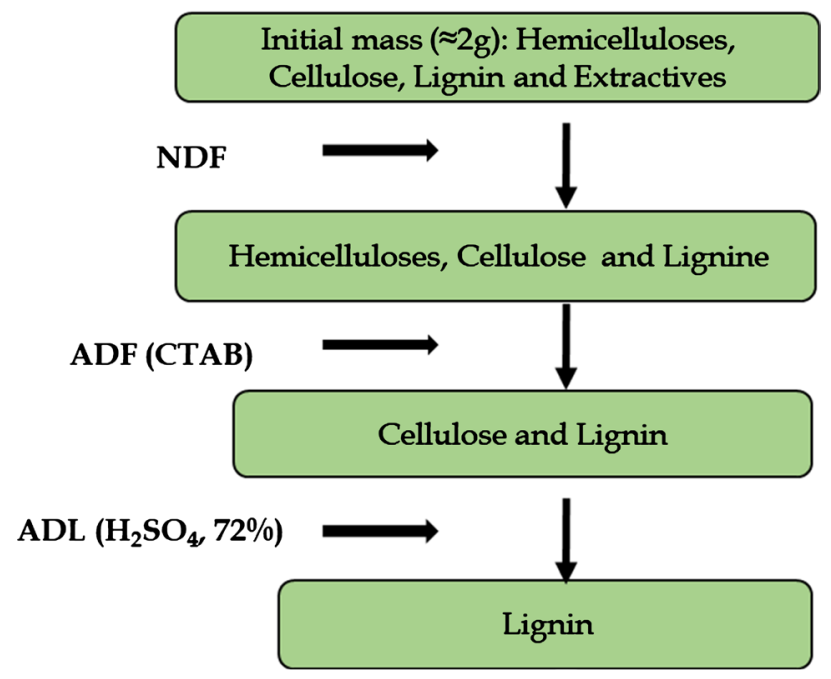

Figure 1. Extraction process of pseudo-components. 
Table 1. Composition CHNSO* and HHV of several biomasses used in this study.

\begin{tabular}{|c|c|c|c|c|c|c|c|c|c|c|}
\hline \multirow{2}{*}{\multicolumn{2}{|c|}{ Samples }} & \multicolumn{5}{|c|}{ Ultimate analysis } & \multicolumn{3}{|c|}{ Proximate analysis } & \multirow{2}{*}{$\begin{array}{c}\mathrm{HHV} \\
(\mathrm{MJ} / \mathrm{kg})\end{array}$} \\
\hline & & $\% \mathrm{C}$ & $\% \mathrm{H}$ & $\% \mathrm{~N}$ & $\% \mathrm{O}^{*}$ & $\% \mathrm{~S}$ & $\% \mathrm{VM}$ & $\% \mathrm{FC}$ & $\% \mathrm{~A}$ & \\
\hline \multirow{4}{*}{ Raw } & PNS & 47.12 & 5.77 & 0.86 & 44.11 & - & 61.62 & 23.06 & 2.12 & 18.02 \\
\hline & CNS & 50.79 & 6.70 & 0.76 & 38.17 & - & 47.59 & 38.15 & 3.57 & 22.85 \\
\hline & PLS & 42.57 & 5.27 & 0.46 & 49.30 & 0.68 & 74.17 & 9.55 & 2.38 & 18.76 \\
\hline & MS & 40.54 & 5.40 & 0.80 & 47.77 & - & 83.10 & 11.41 & 5.47 & 16.35 \\
\hline \multirow{4}{*}{ Char } & PNS & 84.53 & 1.09 & 1.09 & 6.02 & - & 7.69 & 81.09 & 7.25 & 28.60 \\
\hline & CNS & 78.31 & 1.30 & 1.23 & 6.11 & - & 17.47 & 70.57 & 13.02 & 26.51 \\
\hline & PLS & 79.86 & 0.89 & 0.61 & 8.69 & 0.91 & 17.66 & 70.36 & 9.92 & 29.69 \\
\hline & MS & 72.70 & 1.13 & 0.97 & 9.20 & - & 28.82 & 55.18 & 15.98 & 24.93 \\
\hline
\end{tabular}

of the raw samples content of carbon, volatiles matter and calorific values vary by $40 \%-50 \%, 45 \%-85 \%$ and $16 \%-23 \% \mathrm{MJ} \cdot \mathrm{kg}^{-1}$ respectively. On the other hand, these values vary considerably for those of $70 \%-85 \%, 7 \%-30 \%$ and $24-$ $30 \mathrm{MJ} \cdot \mathrm{kg}^{-1}$. Suggesting that the increase in calorific value of samples is due to the increase in carbon. The calorific value is defined in relation to unit of mass; it represents the amount of energy contained in a unit of mass of the fuel. The minerals content present in the biodegradable fraction promotes the production of ash during combustion. In general, ash is composed predominantly of silica (Si), calcium $(\mathrm{Ca})$, magnesium $(\mathrm{Mg})$, potassium $(\mathrm{K})$ and phosphorus $(\mathrm{P})$ [8] [9] [10] [11].

\subsection{Thermogravimetric Analysis}

After the chemical composition analysis, it is important to analyze the thermal behavior of these biomasses as a function of the rise in temperature. Generally, the major constituents of biomass are cellulose, hemicellulose, lignin, inorganic and some extractives, which have different thermal behavior during pyrolysis. The lignocellulosic compounds study is relevant to pyrolysis because decomposition of these materials occurs at different temperature. Yang et al., 2007; developed that thermal decomposition by pyrolysis of major components of hemicellulose, cellulose and lignin was shown between $200^{\circ} \mathrm{C}-315^{\circ} \mathrm{C}, 315^{\circ} \mathrm{C}-400^{\circ} \mathrm{C}$ and $160^{\circ} \mathrm{C}$ $900^{\circ} \mathrm{C}$ respectively [12]. The kinetic measurements for pyrolysis were performed in simultaneous thermal analyzer used TG-DTA LABSYS Evo instrument, equipped with $\mathrm{N}_{2}$ or $\mathrm{O}_{2}$ flow device and data acquisition system. The first weight loss corresponded to moisture content where a constant weight was reached. In general, the main decomposition of lignocellulosic biomass by pyrolysis process takes place from the range of $200^{\circ} \mathrm{C}-400^{\circ} \mathrm{C}$, where, cellulose and hemicellulose are decomposed [3]. This part was attribute for the devolatilization of particular matter of fuels. Hemicelluloses play a significant role in the reactions of ignition and propagation of pyrolysis analysis [13], whose xylans are most reactive and very sensitive to the reactions of degradation and dehydration. For the thermal 
degradation of cellulose one distinguishes two stages. The first stage ranging between $200^{\circ} \mathrm{C}-280^{\circ} \mathrm{C}$ [13], slightly endothermic corresponds to intermolecular dehydration train the formation of anhydrocellulose intermediates to form chars, tars, carbon oxides and water [14] leading to the degradation of the molecule out of coal and volatile after $280^{\circ} \mathrm{C}$. The second stage consists with the production of chars and tars by an exothermic reaction of depolymerization beyond $280^{\circ} \mathrm{C}$. Hemicelluloses being most sensitive to heat, there are two steps during decomposition. The first step involves fragmentation of polymers, and the second involves the production of monomers, which decompose into volatile products. Hemicelluloses produce more gas than the cellulose at the expense of tar and char. Xylose is the main component of hemicellulose, his decomposition produces acetic acid, furfural, furanone, formaldehyde, and gases ( $\mathrm{CO}, \mathrm{CO}_{2}$ and $\mathrm{C}_{\mathrm{x}} \mathrm{H}_{\mathrm{y}}$ ). Cellulose is the main material of wood by Shafizadeh (1982) study, he offers an inert atmosphere pyrolysis model permit to understand the ranges of cellulose degradation temperatures and their products. The author shows that below $250^{\circ} \mathrm{C}$ there is a dehydration reaction by reducing the degree of polymerization resulting in the removal of water. Between $250^{\circ} \mathrm{C}$ and $300^{\circ} \mathrm{C}$, there material fragilities producing carbon monoxide $(\mathrm{CO})$ and water $\left(\mathrm{H}_{2} \mathrm{O}\right)$. The depolymerization step starts at about $300^{\circ} \mathrm{C}$ formation involving free radicals and levoglucosan. Above $300^{\circ} \mathrm{C}$ levoglucosan decomposes and vaporizes to form water, Formica acid, acetic acid and phenols [15]. The lignin starts decomposing at low temperatures between $160^{\circ} \mathrm{C}-170^{\circ} \mathrm{C}$ and continuous to decompose at low rate until $900^{\circ} \mathrm{C}$ [16], this part favorite production of ash content in oxidant atmosphere. From where the groupings hydroxyl $(\mathrm{OH})$ catalyzed the rupture of functions $\mathrm{COOH}$ at low temperature $\left(\mathrm{T}<200^{\circ} \mathrm{C}\right)$ involving the carbon dioxide and water formation. Figure 2 illustrates the thermal decomposition profile of our four samples used in this study in inert atmosphere.

Biomass pyrolysis is a complex process, according to describe three independent parallel reactions, each corresponding to the decomposition of hemicellulose, cellulose and lignin components. This pyrolysis reaction could described the thermal profile for decomposition of PNS, CNS, PLS and MS in nitrogen atmosphere. The maximal variation of weight is $68 \%, 71 \%, 80 \%$ and $75 \%$ for PLS, PNS, CNS and MS respectively at $5^{\circ} \mathrm{C} \cdot \mathrm{min}^{-1}$ heating rate ramp. For all curves present here, a peak around $100^{\circ} \mathrm{C}$ corresponds to dehydration of biomass.

Tsamba et al., 2006; showed the maximal mas loss of cashew nut shell for heating rate between $247^{\circ} \mathrm{C}$ and $420^{\circ} \mathrm{C}$ [16]. They distinguished two peaks: one is found to $320^{\circ} \mathrm{C}$ and the other at $395^{\circ} \mathrm{C}$, respectively, corresponding to hemicellulose and cellulose decomposition with a maximal weight loss mass of $77 \%$. In this paper, the two peaks (Figure 3 ) are distinguished one $307^{\circ} \mathrm{C}$ with a weight loss of $42 \%$, and the other at $428^{\circ} \mathrm{C}$ with a weight loss of $70 \%$ for $5^{\circ} \mathrm{C} \cdot \mathrm{min}^{-1}$ of heating rate. However, these previous results confirm that these peaks corresponding decomposition of the hemicellulose and cellulose, and reaction continuous to 

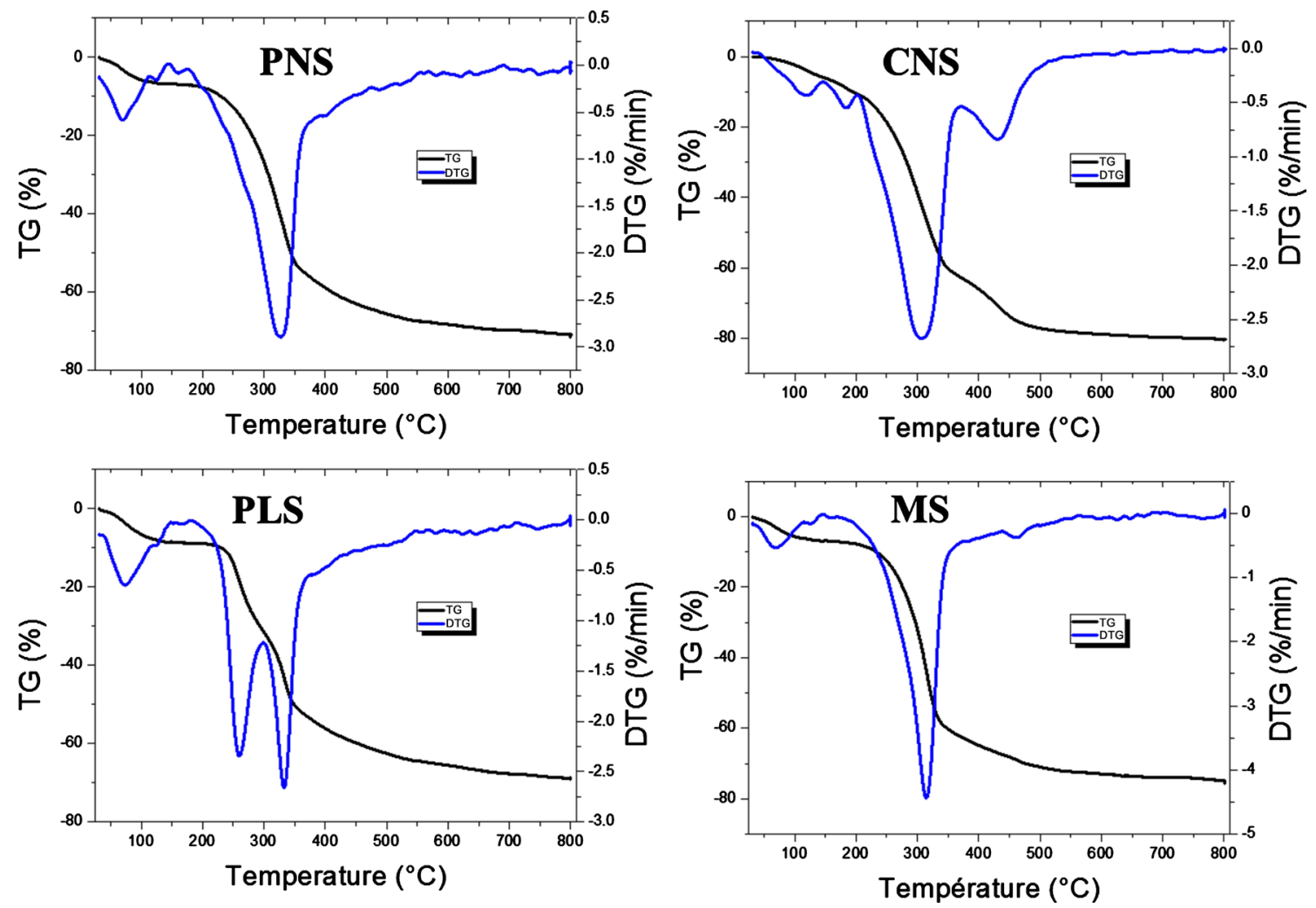

Figure 2. Thermogravimetric analysis under nitrogen atmosphere.

decomposition of the lignin to the surrounding $500^{\circ} \mathrm{C}$. Study conducted by Jeguirim et al, 2014. On the thermal decomposition of palm kernel shells with a ramp of $5^{\circ} \mathrm{C} \cdot \mathrm{min}^{-1}$, they showed presence of two peaks in the devolatilization stage [17]. The first peak start at $261^{\circ} \mathrm{C}$ with mass loss rate of $0.04 \% . \mathrm{s}^{-1}$ $\left(2.4 \% \cdot \mathrm{min}^{-1}\right)$ attributed to decomposition of hemicelluloses; the second occurs at $343^{\circ} \mathrm{C}$ with a maximum mass loss rate of $0.062 \% \cdot \mathrm{s}^{-1}\left(3.72 \% \cdot \mathrm{min}^{-1}\right)$ attributed to cellulose decomposition. We distinguished these two peaks in this work (Figure 3), one at $257^{\circ} \mathrm{C}$ and the other at $337^{\circ} \mathrm{C}$ and their mass loss are $18 \%$ and $46 \%$ respectively. Therefore, these two peaks can be attributed for decomposition of hemicellulose and cellulose. The first peak corresponds to the decomposition of hemicellulose and the second peak to the decomposition of cellulose. There is a pointed peak for peanut shells at $328^{\circ} \mathrm{C}$ with a weight loss of $46 \%$ and the maximum mass loss rate of $2.89 \% \cdot \mathrm{min}^{-1}$. This peak was confirmed by authors to $339^{\circ} \mathrm{C}$ with mass loss rate of $0.080 \% \cdot \mathrm{s}^{-1}\left(4.8 \% \cdot \mathrm{min}^{-1}\right)$ [17] and at $332^{\circ} \mathrm{C}$ with a weight loss of $60.5 \%$ but an ramp of $10^{\circ} \mathrm{C} \cdot \mathrm{min}^{-1}$ [18]. It can be noted that the coal yield of PLS, PNS, CNS and MS vary by $32 \%, 29 \%, 20 \%$ and $25 \%$ respectively during inert atmosphere pyrolysis.

In oxidizing atmosphere, it is found that there remains a very low ash rate of less than $5 \%$ for the four samples. The rate of volatiles varies by about $96 \%, 98 \%$, $100 \%$ and $97 \%$ respectively for peanut shells, cashew nut shells, palm nut shells and millet stem. There is total carbonization and the products of ash are very small amount. ATG shows that mass loss starts at about $100^{\circ} \mathrm{C}$ of water evaporation 

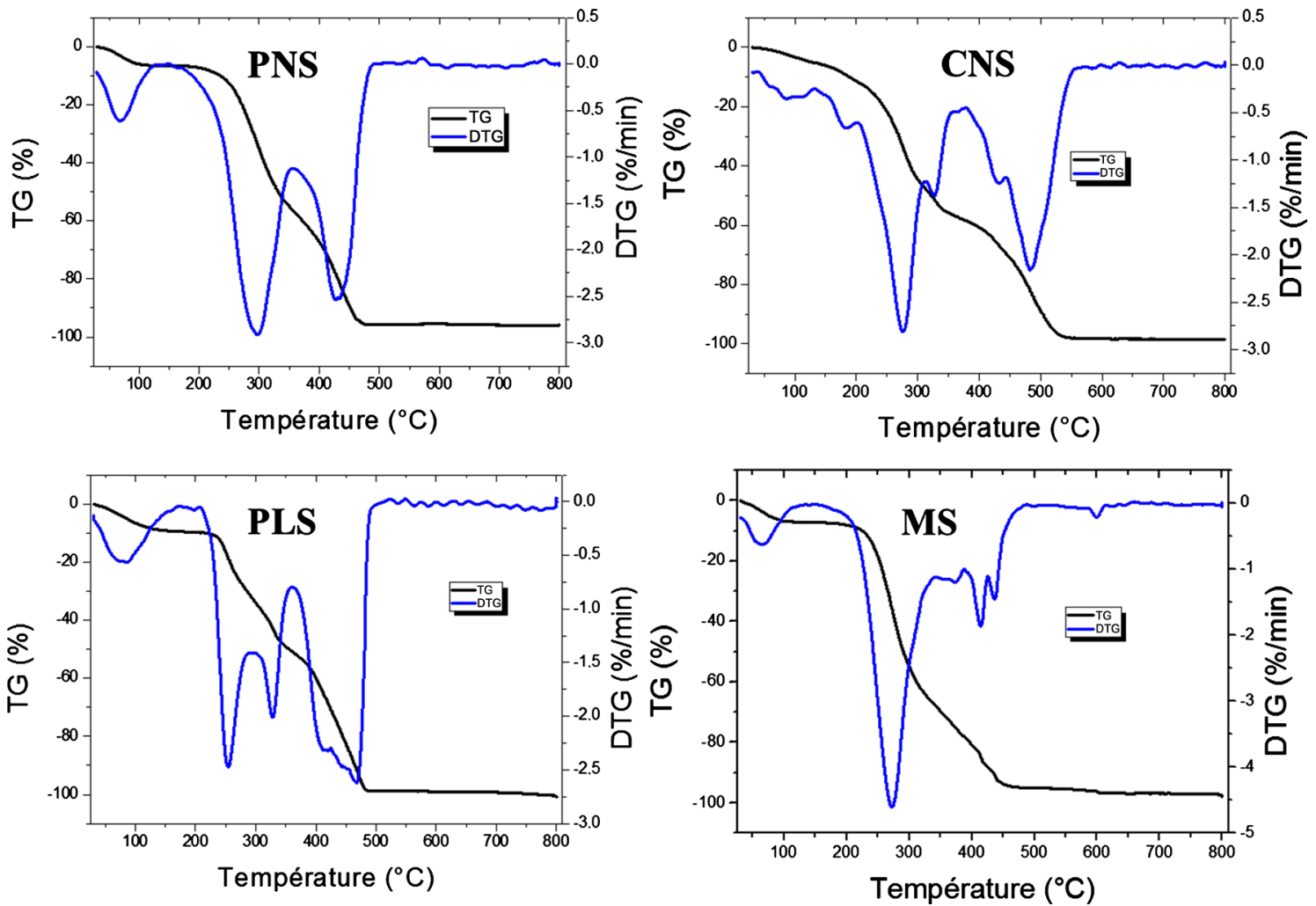

Figure 3. Thermogravimetric analysis under oxidizing atmosphere.

on the three biomass residues. PNS have two major peaks one at $298^{\circ} \mathrm{C}$ with a weight loss of $35 \%$ and the other at $428^{\circ} \mathrm{C}$ than mass loss of $97 \%$. CNS has two peaks in the devolatilization stage, one at $276^{\circ} \mathrm{C}$ with a weight loss of $34 \%$ and the other at $328^{\circ} \mathrm{C}$ with a weight loss of $54 \%$, the third largest peak obtained after devolatilization is around $483^{\circ} \mathrm{C}$ with weight loss $82 \%$. Cashew nut combustion is dangerous because of the cashew nut shell liquid (CNSL), and smoke that irritating eyes. Indeed, the main constituents the first is at $253^{\circ} \mathrm{C}$ with a weight loss of $16 \%$, the second at $325^{\circ} \mathrm{C}$ with a weight loss of $41 \%$ and the third largest and blunt to $467^{\circ} \mathrm{C}$ with a weight loss of $91 \%$. MS has two major peaks, the first at $273^{\circ} \mathrm{C}$ with a weight loss of $33 \%$ and the second at $414^{\circ} \mathrm{C}$ with a weight loss at $86 \%$.

\subsection{Extraction of the Lignocellulosic Components}

Lignocellulosic biomass is one of the most abundant renewable resources on earth, and certainly one of the least expensive. Its thermochemical conversion for combustible use would make it possible to meet the energy needs, hitherto covered mainly by petroleum products, while generating new opportunities for the agriculture in the world. The major components of dry lignocellulosic fibers are cellulose, hemicelluloses and lignin [19]. There are other minority products such as extractable by organic solvents. The chemical composition of the fibers depends on the source. According to our results, cellulose and lignin are the main components of the samples selected in this study. The shells have a high content of cellulose and lignin (Table 2) with more than $60 \%$ of the residues 
content, which is a significant factor in the energy content of fuels. That is to say for a better fuel, it is necessary to have a large amount of cellulose and lignin because its thermal decomposition requires more energy with higher temperatures at the environments at $500^{\circ} \mathrm{C}$.

\subsection{Structure (ESEM)}

Electronic scan microscopy makes it possible to obtain images of high-resolution of the surface of the sample. It is generally used to study morphology in $3 \mathrm{D}$ of surface or an object, but also to have an idea on the chemical composition by microanalysis X. PNS and MS have fragile and fibrous bodies. PLS has a rigid body and his pores are on different dimensions. The CNS has no pores, no fibers and a very rigid body. This morphological difference plays a very important part in energy valorization. From where we have differences on their heating value, which depends on the density of the matter. Figure 4 illustrates the images

Table 2. Lignocellulosic composition of biomass residues.

\begin{tabular}{ccccc}
\hline Co-products & \% Hemicellulose & \% Cellulose & \% Lignin & \% Extractives \\
\hline PNS & 13.01 & 32.35 & 34.80 & 19.82 \\
PLS & 13.39 & 24.20 & 45.03 & 17.36 \\
CNS & 06.61 & 34.94 & 35.29 & 23.13 \\
MS & 18.96 & 39.67 & 11.40 & 29.95 \\
\hline
\end{tabular}
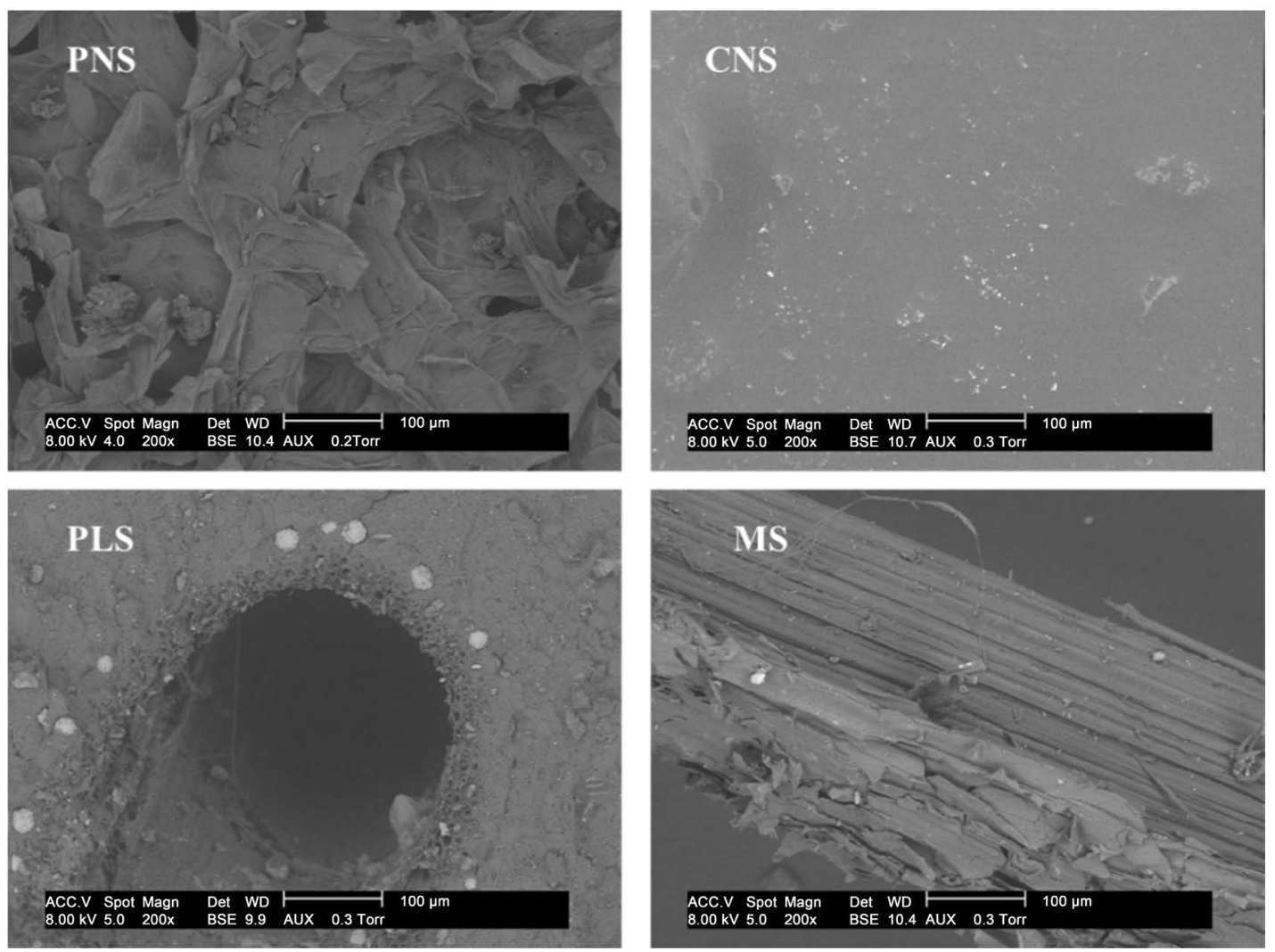

Figure 4. Morphology of surface by PNS, CNS, PLS and MS. 
obtained by ESEM at $100 \mu \mathrm{m}$ magnification for the four samples.

\subsection{Production of Biochars}

Biochar is a stable carbonaceous product made from by-products of animal or vegetable biomass, or organic waste. Biochar is produced under reducing thermal conditions and must have a well-defined and controlled quality. A wide range of organic raw materials can be used for the production of biochar, but for its manufacture it is necessary to respect the requirements of durability, i.e. not to use materials competitive with food or animal feed and plant nutrition. This is how pyrolysis and charcoal gases are obtained, the consistency of which corresponds to that of the wood. In the context of the diversification of energy resources in Senegal, biochar stands out as an alternative to charcoal in the context of preserving our environment. Figure 5 shows the image of briquettes produced from PNS, CNS and MS, whose binder correspond to clay. But it must be understood that it is difficult to identify with the naked eye the briquettes for each residues type.

\section{Conclusion}

In this study the thermogravimetric analysis used allowed us to understand the thermal behavior of the samples at different atmospheres. It can be said that the thermal efficiency of the chars is higher than that of the raw biomass because the chars have the highest calorific value. These values varied from $16 \mathrm{MJ} \cdot \mathrm{kg}^{-1}$ to 19 $\mathrm{MJ} \cdot \mathrm{kg}^{-1}$ for the raw biomass and from $24 \mathrm{MJ} \cdot \mathrm{kg}^{-1}$ to $30 \mathrm{MJ} \cdot \mathrm{kg}^{-1}$ by chars. The calorific value strongly depends on the carbon content which is directly related to the pseudo-component content. Cellulose composition, which is a very rich carbon skeleton, varies from 32.35\%, 24.20\%, 34.94\% and 39.67\% for PNS, PLS, CNS and MS. However, it can also be deduced that their chemical composition depends strongly on the nature and origin of the sample. So this study will allow us to characterize the fuel briquettes obtained from the residues of biomass. These residues therefore exhibit good thermal behavior; it's necessary to study the different possible emissions during combustion. The characterization of the oil (tars) produced would be very important for the rest of the work aimed at the manufactured of fuel briquettes (or biochars). It would also be important to determine the energy efficiency of these biofuels in the different types of improved stoves used at the national level.

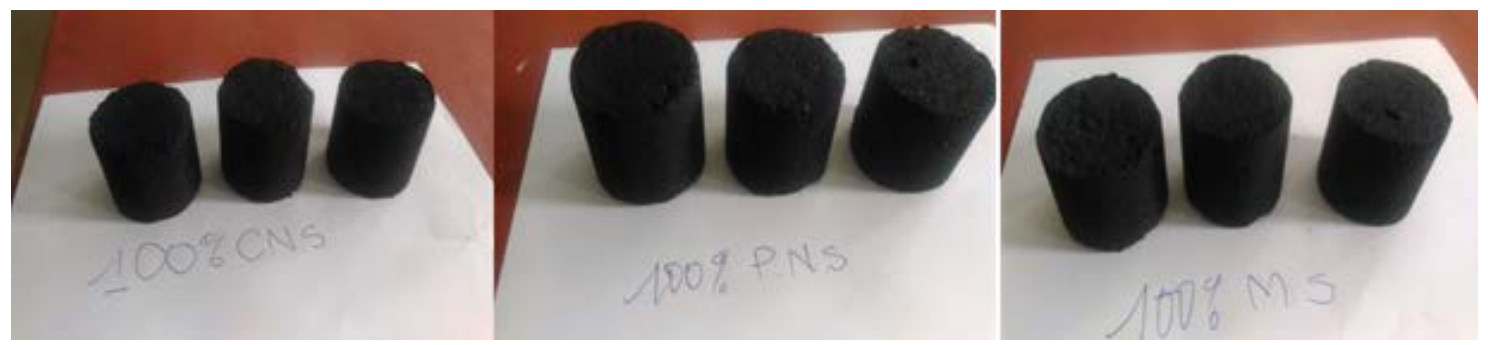

Figure 5. Image of fuel briquettes of PNS, CNS, PLS and MS. 


\section{Acknowledgements}

This work is supported by:

- Assane Seck University of Ziguinchor;

- French Cooperation Scholarship at French Embassy in Senegal.

\section{Conflicts of Interest}

The authors declare no conflicts of interest regarding the publication of this paper.

\section{References}

[1] Yang, X., Choi, H.S., Park, C. and Kim, S.W. (2015) Current States and Prospects of Organic Waste Utilization for Biorefineries. Renewable and Sustainable Energy Reviews, 49, 335-349. https://doi.org/10.1016/j.rser.2015.04.114

[2] Liu, Z., Jiang, Z., Fei, B. and Liu, X. (2013) Thermal Decomposition Characteristics of Chinese Fir. BioResources, 8, 5014-5024. https://doi.org/10.15376/biores.8.4.5014-5024

[3] Sharma, A., Pareek, V. and Zhang, D. (2015) Biomass Pyrolysis-A Review of Modelling, Process Parameters and Catalytic Studies. Renewable and Sustainable Energy Reviews, 50, 1081-1096. https://doi.org/10.1016/j.rser.2015.04.193

[4] PAM (2014) Analyse Globale de la Vulnérabilité, de la Sécurité Alimentaire et de la Nutrition (AGVSAN) Sénégal. 1-96.

[5] Burhenne, L., Messmer, J., Aicher, T. and Laborie, M.P. (2013) The Effect of the Biomass Components Lignin, Cellulose and Hemicellulose on TGA and Fixed Bed Pyrolysis. Journal of Analytical and Applied Pyrolysis, 101, 177-184. https://doi.org/10.1016/j.jaap.2013.01.012

[6] Seo, D.K., Park, S.S., Hwang, J. and Yu, T.U. (2010) Study of the Pyrolysis of Biomass Using Thermo-Gravimetric Analysis (TGA) and Concentration Measurements of the Evolved Species. Journal of Analytical and Applied Pyrolysis, 89, 66-73. https://doi.org/10.1016/j.jaap.2010.05.008

[7] Martens, D.A. and Loeffelmann, K.L. (2002) Improved Accounting of Carbohydrate Carbon from Plants and Soils. Soil Biology and Biochemistry, 34, 1393-1399. https://doi.org/10.1016/S0038-0717(02)00082-2

[8] Demirbas, A. (2005) Potential Applications of Renewable Energy Sources, Biomass Combustion Problems in Boiler Power Systems and Combustion Related Environmental Issues. Progress in Energy and Combustion Science, 31, 171-192. https://doi.org/10.1016/j.pecs.2005.02.002

[9] Qin, K. and Thunman, H. (2015) Diversity of Chemical Composition and Combustion Reactivity of Various Biomass Fuels. Fuel, 147, 161-169. https://doi.org/10.1016/j.fuel.2015.01.047

[10] Liu, Z. and Han, G. (2015) Production of Solid Fuel Biochar from Waste Biomass by Low Temperature Pyrolysis. Fuel, 158, 159-165. https://doi.org/10.1016/j.fuel.2015.05.032

[11] Binici, H. and Aksogan, O. (2017) Insulation Material Production from Onion Skin and Peanut Shell Fibres, Fly Ash, Pumice, Perlite, Barite, Cement and Gypsum. Materials Today Communications, 10, 14-24. https://doi.org/10.1016/j.mtcomm.2016.09.004 
[12] Yang, H., Yan, R., Chen, H., Lee, D.H. and Zheng, C. (2007) Characteristics of Hemicellulose, Cellulose and Lignin Pyrolysis. Fuel, 86, 1781-1788.

https://doi.org/10.1016/j.fuel.2006.12.013

[13] Rousset, P., Turner, I., Donnot, A. and Perré, P. (2006) Choix d'un modèle de pyrolyse ménagée du bois à l'échelle de la microparticule en vue de la modélisation macroscopique. Annals of Forest Science, 63, 213-229.

https://doi.org/10.1051/forest:2005113

[14] Klass, D. (1998) Thermal Conversion: Pyrolysis and Liquefaction. In: Klass, D.L., Ed., Biomass for Renewable Energy, Fuels, and Chemicals, Elsevier, Amsterdam, 225-269. https://doi.org/10.1016/B978-012410950-6/50011-8

[15] Shafizadeh, F. (1982) Introduction to Pyrolysis of Biomass. Journal of Analytical and Applied Pyrolysis, 3, 283-305. https://doi.org/10.1016/0165-2370(82)80017-X

[16] Tsamba, A.J., Yang, W. and Blasiak, W. (2006) Pyrolysis Characteristics and Global Kinetics of Coconut and Cashew Nut Shells. Fuel Processing Technology, 87, 523-530. https://doi.org/10.1016/j.fuproc.2005.12.002

[17] Jeguirim, M., Bikai, J., Elmay, Y., Limousy, L. and Njeugna, E. (2014) Thermal Characterization and Pyrolysis Kinetics of Tropical Biomass Feedstocks for Energy Recovery. Energy for Sustainable Development, 23, 188-193. https://doi.org/10.1016/j.esd.2014.09.009

[18] Zhu, G., Zhu, X., Xiao, Z., Zhou, R., Zhu, Y. and Wan, X. (2014) Kinetics of Peanut Shell Pyrolysis and Hydrolysis in Subcritical Water. Journal of Material Cycles and Waste Management, 16, 546-556. https://doi.org/10.1007/s10163-013-0209-7

[19] Yaman, S. (2004) Pyrolysis of Biomass to Produce Fuels and Chemical Feedstocks. Energy Conversion and Management, 45, 651-671. https://doi.org/10.1016/S0196-8904(03)00177-8 